\title{
SEX DIFFERENCES IN TIBIOCALCANEAL KINEMATICS
}

doi: 10.2478/humo-2014-0010

\author{
JONATHAN SINCLAIR ${ }^{1}$ *, PAUL J. TAYLOR ${ }^{2}$ \\ ${ }^{1}$ School of Sport Tourism and Outdoors, University of Central Lancashire, Preston, United Kingdom \\ ${ }^{2}$ School of Psychology, University of Central Lancashire, Preston, United Kingdom
}

\begin{abstract}
Purpose. Female runners typically suffer more from chronic running injuries than age-matched males, although the exact biomechanical mechanisms behind the increased susceptibility of female runners are unknown. This study aimed to compare sex differences in tibiocalcaneal kinematics during the stance phase of running. Methods. Twenty male and twenty female participants ran at $4.0 \mathrm{~m} \cdot \mathrm{s}^{-1}$. Tibiocalcaneal kinematics were measured using an eight-camera motion analysis system and compared using independent samples $t$ tests. Results. Peak eversion and tibial internal rotation angles were shown to be significantly greater in female runners. Conclusions. Based on these observations, it was determined that female runners may be at increased risk from chronic injury development in relation to excessive tibiocalcaneal motions in the coronal and transverse planes.
\end{abstract}

Key words: male, female, kinematics, injury

\section{Introduction}

Running is a popular sporting discipline for both males and females [1]. A rapid growth in distance running participation has been witnessed amongst the female population [2]. Although running is clearly beneficial to physiological health, the risk of chronic injury is also well documented [1]. Female runners typically suffer more from chronic injuries than age-matched males $[3,4]$.

It has been postulated that differences in lower extremity running biomechanics may be the mechanism by which females sustain different injury patterns in comparison with males [4]. Epidemiological analyses show that females are twice as likely to sustain an injury related to running [3], yet the specific aetiology of these injuries is still not fully understood [1]. Differences in both the kinetics and kinematics during running have been postulated as contributing factors to the increased susceptibility of females to injuries as a result of running $[4,5]$. Sinclair et al. [4] showed that females were associated with significantly greater knee abduction and knee internal rotation in comparison with males, which they hypothesized were implicated in the aetiology of injury. Similarly, Ferber et al. [5] showed a significantly greater hip internal rotation and abduction and knee abduction in female runners. With regards to the kinetic differences between sexes, both Hennig [6] and Stefanyshyn et al. [7] showed that vertical rates of loading were significantly greater in female runners. Nonetheless although sex differences in running biomechanics have been examined, there is still a need for further examination into the biomechanical param-

\footnotetext{
* Corresponding author.
}

eters that might provide insight into the aetiology of injury in females.

During running, excessive coronal plane eversion of the ankle and internal rotation of the tibial segment during the stance phase of running have been implicated in the aetiology of running injuries [8-10]. The movement of the foot and shank are related, causing the tibial segment to rotate internally between touchdown and mid-stance $[11,12]$. The transfer from ankle eversion to tibial internal rotation has been shown to differ widely among individuals $[11,12]$. Yet, to date, it has not been established as to whether sex differences in tibiocalcaneal kinematics exist and how they might influence this coupling pattern. This study therefore aims to determine whether differences in tibiocalcaneal kinematics may exist between male and female recreational runners. A study of this nature may provide further insight into the increased incidence of injuries in female runners.

\section{Material and methods}

\section{Participants}

Twenty males (age $25.14 \pm 4.73$ years, height $1.78 \pm$ $0.08 \mathrm{~m}$ and body mass $77.19 \pm 8.28 \mathrm{~kg}$ ) and twenty females (age $24.84 \pm 5.08$ years, height $1.67 \pm 0.09 \mathrm{~m}$ and body mass $66.94 \pm 7.29 \mathrm{~kg}$ ) volunteered to take part in the current investigation. Participants were recreational runners who trained at least three times per week. All were free from musculoskeletal pathology. All runners were classified as rearfoot strikers as they exhibited a clear first peak in their vertical ground reaction force time-curve [13]. All participants provided written informed consent and ethical approval was obtained from 
J. Sinclair, P.J. Taylor, Sex differences in tibiocalcaneal kinematics

the University of Central Lancashire School of Psychology in accordance with the principles documented in the Declaration of Helsinki.

\section{Procedure}

Participants ran at $4.0 \mathrm{~m} \cdot \mathrm{s}^{-1} \pm 5 \%$ across a biomechanics laboratory, completing five successful trials. Running velocity was quantified using Newtest 300 timing gates (Newtest, Finland). Along the running path participants struck a piezoelectric force plate (Kistler Instruments, UK) [14] operating at $1000 \mathrm{~Hz}$ with their dominant foot. The stance phase was determined as the period over which $>20 \mathrm{~N}$ of vertical force was applied to the force plate [15].

Kinematic information was captured at $250 \mathrm{~Hz}$ using an eight-camera motion analysis system (Qualisys Medical, Sweden). Calibration of the motion capture system was performed before each data collection session. The calibrated anatomical systems technique (CAST) was utilised to quantify tibiocalcaneal kinematics [16]. The ankle joint was delineated as a function of the end points of the distal aspect of the tibial and the proximal end of the foot. To define the anatomical frames of the right foot and shank, retro-reflective markers were positioned onto the calcaneus, $1^{\text {st }}$ and $5^{\text {th }}$ metatarsal heads, medial and lateral malleoli and medial and lateral epicondyle of the femur. A carbon-fibre tracking cluster comprising of four retro-reflective markers was positioned onto the shank segment and secured using rigid tape. The foot was tracked using the calcaneus and $1^{\text {st }}$ and $5^{\text {th }}$ metatarsal markers. Static calibration trials (not normalized to standing posture) were obtained with the participant in the anatomical position in order for the positions of the anatomical markers to be referenced in relation to the tracking cluster/markers. The reliability of this measurement technique has been shown to be very high [17].

\section{Data processing}

Retro-reflective markers were digitized using Qualisys Track Manager (Medical AB, Sweden) in order to appropriate markers and exported as C3D files. Three-dimensional kinematics were quantified using Visual 3-D (C-Motion, USA) after marker displacement data were smoothed using a low-pass Butterworth $4^{\text {th }}$ order zero-lag filter at a cut off frequency of $12 \mathrm{~Hz}$ [18]. Three-dimensional kinematics were calculated using an XYZ sequence of rotations (where $X$ represents sagittal plane, Y represents coronal plane and $Z$ represents transverse plane rotations) [19]. All kinematic waveforms were normalized to $100 \%$ of the stance phase; the processed trials were then averaged. To quantify ankle kinematics, the foot segment co-ordinate system was referenced in relation to the tibial segment, whilst tibial internal rotation was calculated as a function of the tibial co-ordinate system in

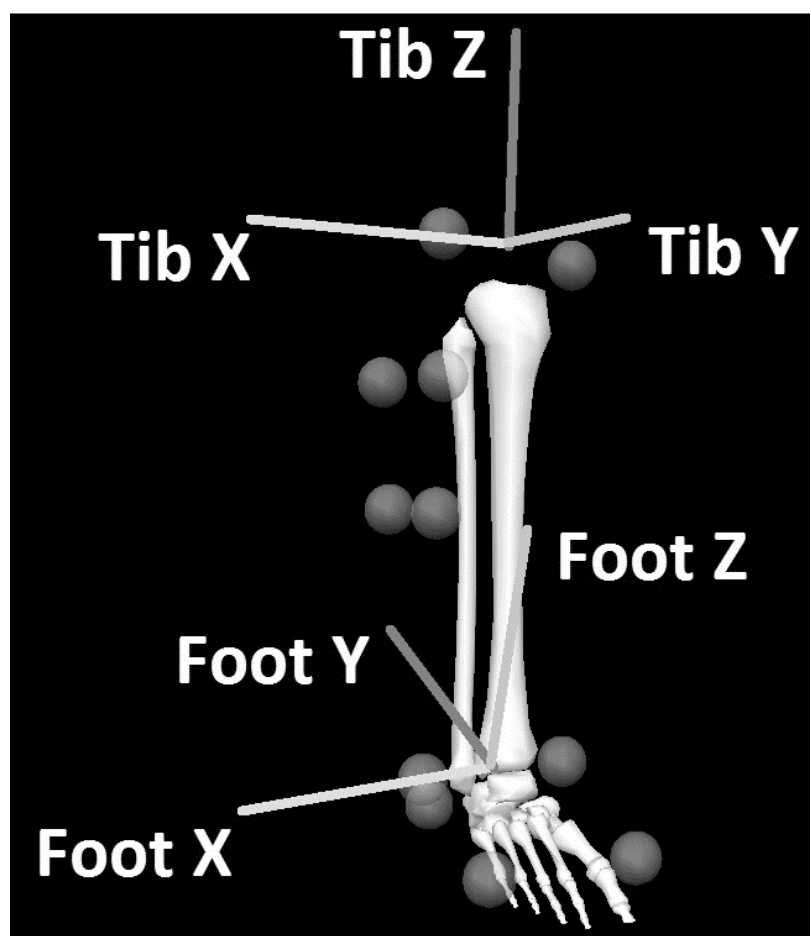

Figure 1. Tibial and foot segments with reference segment coordinate system axes:

$\mathrm{X}$ - sagittal plane; $\mathrm{Y}$ - coronal plane, $\mathrm{Z}$ - transverse plane

relation to the foot in accordance with previous work [9]. Discrete 3-D kinematic measures from the ankle and tibia which were extracted for statistical analysis were 1) angle at footstrike, 2) angle at toe-off, 3) range of motion from footstrike to toe-off during stance, 4) peak eversion/tibial internal rotation, 5) relative range of motion (representing the angular displacement from footstrike to peak angle) and 6) eversion/tibial internal (EV/TIR) ratio. These variables have been defined as being clinically meaningful parameters by previous investigations which have examined tibiocalcaneal kinematics [8].

Footwear

Participants wore the same footwear throughout the study, Asics GT 2160 in men's sizes 5-10 UK (Asics, Japan).

\section{Statistical analyses}

To compare sex differences in tibiocalcaneal kinematic parameters, independent $t$ tests were utilized with significance accepted at the $p<0.05$ level. Effect sizes were calculated using Cohen's $d$ statistic. The Shapiro-Wilk statistic for each condition confirmed that the data were normally distributed. Intra-class correlations (ICC) were employed to determine the sex differences in transfer function between eversion and tibial internal rotation waveforms from the stance phase in accordance with Sinclair et al. [8]. All statistical procedures were conducted using SPSS 21.0 (IBM, USA). 

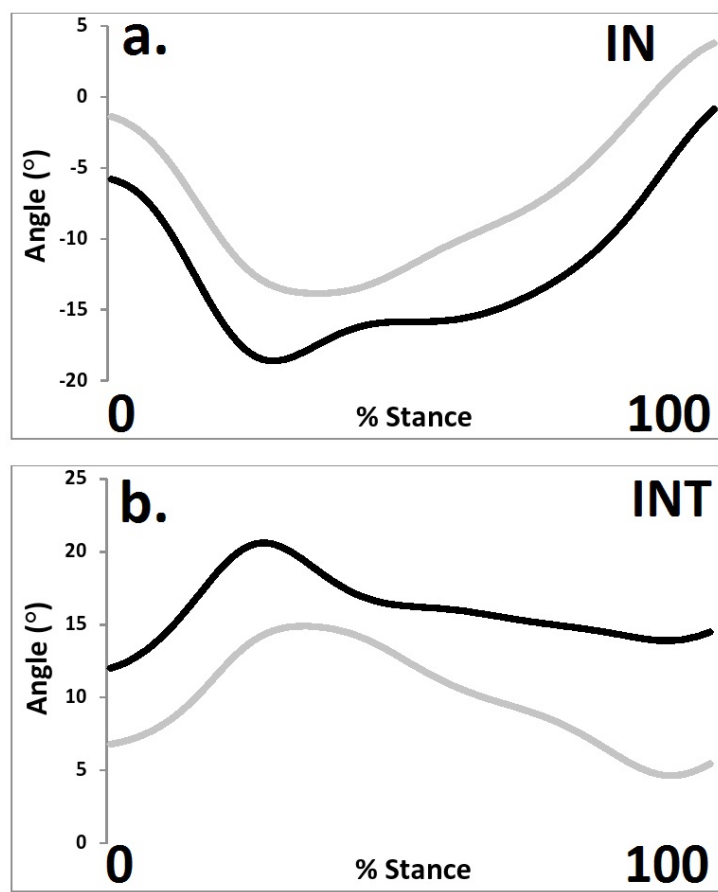

Figure 2. Tibiocalcaneal kinematics as a function of sex. Black line - female, grey line - male, a - ankle coronal plane angle, $\mathrm{b}$ - tibial internal rotation angle, IN - inversion, INT - internal

\section{Results}

The results indicate that whilst the stance phase kinematic curves from males and females were quantitatively similar, significant differences were observed between sexes. Figure 2 and Table 1 present the mean tibiocalcaneal kinematic parameters and stance phase joint angle curves obtained as a function of sex.

Table 1. Tibiocalcaneal kinematics as a function of sex

\begin{tabular}{lrc}
\hline Ankle eversion/inversion & \multicolumn{1}{c}{ Male } & \multicolumn{1}{c}{ Female } \\
\hline Y - inversion $(+) /$ eversion $(-)$ & & \\
Angle at footstrike $\left(^{\circ}\right)$ & $-1.58 \pm 5.08$ & $-5.51 \pm 6.84$ \\
Angle at toe-off $\left(^{\circ}\right)$ & $3.85 \pm 2.89$ & $-1.76 \pm 5.86 *$ \\
Range of motion $\left(^{\circ}\right)$ & $6.32 \pm 3.55$ & $5.86 \pm 3.10$ \\
Relative range of motion $\left(^{\circ}\right)$ & $11.93 \pm 3.32$ & $12.36 \pm 3.94$ \\
Peak eversion $\left({ }^{\circ}\right)$ & $-11.84 \pm 4.09$ & $-17.36 \pm 6.97 *$ \\
Tibial Internal Rotation & & \\
\hline
\end{tabular}

Z - inversion (+)/eversion (-)

Angle at footstrike $\left(^{\circ}\right)$

$7.09 \pm 6.09 \quad 11.21 \pm 6.70$

Angle at toe-off $\left({ }^{\circ}\right)$

Range of motion $\left(^{\circ}\right.$ )

$5.55 \pm 3.11$

$14.08 \pm 6.85 *$

Relative range of motion $\left(^{\circ}\right)$

$1.65 \pm 4.90$

$2.85 \pm 2.48$

$7.93 \pm 4.29$

Peak tibial internal rotation $\left({ }^{\circ}\right) \quad 14.25 \pm 7.36$

$8.92 \pm 3.00$

EV/TIR ratio

$1.55 \pm 1.76$

$20.17 \pm 7.23 *$

EV/TIR ICC

0.63

$1.32 \pm 1.09$

0.99
In the coronal plane, females were associated with significantly $\left(t_{(38)}=3.99, p<0.05, D=0.92\right)$ greater eversion at toe-off in comparison to males. Females also exhibited significantly $\left(t_{(38)}=4.22, p<0.05 d=0.95\right)$ greater peak eversion in comparison with males. In the transverse plane, it was also shown that tibial internal rotation at toe-off was significantly $\left(t_{(38)}=4.96, p<0.05\right.$, $d=1.10$ ) greater in females compared with males. It was also shown that peak tibial internal rotation was significantly $\left(t_{(38)}=5.11, p<0.05, d=1.18\right)$ greater in females compared with males.

\section{Discussion}

This study aimed to determine whether differences in tibiocalcaneal kinematics may exist between males and females. This represents the first comparative investigation to investigate the differences in tibiocalcaneal kinematics between male and female runners.

The first key observation of the current study is that female runners were associated with significantly greater eversion and tibial internal rotation angles in comparison with males. This finding has potential clinical significance as excessive rearfoot eversion and associated tibial internal rotation parameters are implicated in the aetiology of a number of overuse injuries such as tibial stress syndrome, plantar fasciitis, patellofemoral syndrome and iliotibial band syndrome [20, 21]. This finding therefore suggests that females may be at greater risk from chronic injuries related to excessive eversion/ tibial internal rotation.

Furthermore, it was found that movement coupling between the calcaneus and tibia was strongly influenced by sex. Females exhibited a near complete transfer function from eversion to tibial internal rotation $($ ICC $=0.99$ ) whereas in males this was far less pronounced ( $\mathrm{ICC}=0.63$ ). Thus it appears that males and female runners exhibit distinct tibiocalcaneal coupling patterns. This mechanism is potentially due to sex variations in foot and lower extremity structure [22] and thus it is recommended that future investigations consider this feature.

The findings of the current investigation provide information that supports the increased susceptibility of females to injury. Therefore, given the significant increase in rearfoot eversion observed in female runners, it is recommended that females select running footwear with design characteristics aimed towards the reduction of calcaneal eversion. It is hypothesized that this will serve to reduce the incidence of pathology in female runners.

There are some limitations to the current investigation that should be acknowledged. Markers positioned on the shoe used to measure foot movement may serve as a limitation as the foot segment moves within the shoe itself and thus the accuracy of this technique is questionable. Previous analyses have examined the differences in foot kinematics when using markers positioned on the shoe and those placed onto the skin through holes cut

\footnotetext{
* significant difference
} 
into the shoe. It has been shown that markers positioned onto the shoe can lead to errors particularly in the coronal and transverse planes [19]. However, as cutting holes in the footwear reduces the structural integrity of the shoe upper and may influence runners' perception of the footwear [23], it was determined that the present technique is acceptable. That the current investigation examined only single-segment foot mechanics may also serve as a limitation. While effective, it does not allow articulations of the more intricate foot segments to be quantified, which may also provide insight into the aetiology of injury [24]. As such, whilst this study provides insight into the differences between male and female runners using a single-segment foot model, future work should be conducted examining sex differences using a multiple-segment foot model.

\section{Conclusions}

The current investigation provides new information describing tibiocalcaneal kinematics in male and female runners. On the basis that increases in ankle eversion and tibial internal rotation were noted in female runners, the current investigation may provide insight into the aetiology of different injury patterns observed between sexes. This study supports the notion that females are more susceptible to overuse injuries than males.

Acknowledgements

Our thanks go to Glen Crook for his technical assistance.

\section{References}

1. Taunton J.E., Ryan M.B., Clement D.B., McKenzie D.C., Lloyd-Smith D.R., Zumbo B.D., A prospective study of running injuries: the Vancouver Sun Run "In Training" clinics. Br J Sports Med, 2003, 37 (3), 239-244, doi: 10. 1136/bjsm.37.3.239.

2. Lilley K., Dixon S., Stiles V., A biomechanical comparison of the running gait of mature and young females. Gait Posture, 2011, 33 (3), 496-500, doi: 10.1016/j.gaitpost.2011. 01.002 .

3. Robinson R.L, Nee R.J., Analysis of hip strength in females seeking physical therapy treatment for unilateral patellofemoral pain syndrome. J Orthop Sports Phys Ther, 2007, 37 (5), 232-238, doi:10.2519/jospt.2007.2439.

4. Sinclair J., Greenhalgh A., Edmundson C.J., Brooks D., Hobbs S.J., Gender Differences in the Kinetics and Kinematics of Distance Running: Implications for Footwear Design. Int J Sports Sci Eng, 2012, 6 (2), 118-128.

5. Ferber R., Davis I.M., Williams D.S., Gender differences in lower extremity mechanics during running. Clin Biomech, 2003, 18 (4), 350-357, doi: 10.1016/S02680033 (03)00025-1.

6. Hennig E.M., Gender differences for running in athletic footwear. In: Henning E.M., Stacoff A. (eds.), Proceedings of the $5^{\text {th }}$ Symposium on Footwear Biomechanics. Zurich, Switzerland 2001, 44-45.

7. Stefanyshyn D.J., Stergiou P., Nigg B.M., Rozitis A.I., Goepfert B., Do females require different running foot- wear? In: Proceedings of the $6^{\text {th }}$ Symposium on Footwear Biomechanics Queenstown, New Zealand 2003, 91-92.

8. Sinclair J., Hobbs S.J., Currigan G., Giannandrea M., Taylor P.J., Tibiocalcaneal kinematics during barefoot and in barefoot-inspired shoes in comparison to conventional running footwear. Mov Sport Sci, 2014, 83, 67-75, doi: 10.1051/sm/2013104.

9. Eslami M., Begon M., Farahpour N., Allard P., Forefootrearfoot coupling patterns and tibial internal rotation during stance phase of barefoot versus shod running. Clin Biomech, 2007, 22 (1), 74-80, doi: 10.1016/j.clinbiomech. 2006.08.002.

10. Edington C.J., Frederick E.C., Cavanagh P.R., Rearfoot motion in distance running. In: Cavanagh P.R. (ed.), Biomechanics of distance running. Human Kinetics, Champaign 1990.

11. De Leo A.T., Dierks T.A., Ferber R., Davis I.S., Lower extremity joint coupling during running: a current update. Clin Biomech, 2004, 19 (10), 983-991, doi: 10.1016/j. clinbiomech.2004.07.005.

12. Nawoczenski D.A., Saltzman C.L., Cook T.M., The effect of foot structure on the three-dimensional kinematic coupling behaviour of the leg and rearfoot. Phy Ther, 1998, 78 (4), 404-416.

13. Cavanagh P.R., Lafortune M.A., Ground reaction forces in distance running. J Biomech, 1980, 13 (5), 397-406, doi: 10.1016/0021-9290(80)90033-0.

14. Sinclair J., Hobbs S.J., Taylor P.J., Currigan G., Greenhalgh A., The Influence of Different Force and Pressure Measuring Transducers on Lower Extremity Kinematics Measured During Running. J Appl Biomech, 2014, 30, 166-172, doi: 10.1123/jab.2012-0238.

15. Sinclair J., Edmundson C.J., Brooks D., Hobbs S.J., Evaluation of kinematic methods of identifying gait events during running. Int J Sports Sci Eng, 2011, 5 (3), 188-192.

16. Cappozzo A., Catani F., Della Croce U., Leardini A., Position and orientation in space of bones during movement: anatomical frame definition and determination. Clin Biomech, 1995, 10 (4), 171-178, doi: 10.1016/02680033(95)91394-T.

17. Sinclair J., Taylor P.J., Greenhalgh A., Edmundson C.J., Brooks D., Hobbs S.J., The Test-Retest Reliability of Anatomical Co-Ordinate Axes Definition for the Quantification of Lower Extremity Kinematics During Running. J Hum Kinet, 2012, 35 (1), 15-25, doi: 10.2478/v10078012-0075-8.

18. Winter D.A., Biomechanics and motor control of human movement. John Wiley and Sons, New York 1990.

19. Sinclair J., Taylor P.J., Edmundson C.J., Brooks D., Hobbs S.J., Influence of the helical and six available Cardan sequences on 3D ankle joint kinematic parameters. Sports Biomech, 2012, 11 (3), 430-437, doi: 10.1080/14763141. 2012.656762.

20. Viitasalo J.T., Kvist M., Some biomechanical aspects of the foot and ankle athletes with and without shin splints. Am J Sports Med, 1983, 11 (3), 125-130, doi: 10.1177/ 036354658301100304.

21. Lee S.Y., Hertel J., Lee S.C., Rearfoot eversion has indirect effects on plantar fascia tension by changing the amount of arch collapse. The Foot, 2010, 20 (2-3), 64-70, doi: 10.1016/j.foot.2010.06.003.

22. Wunderlich R.E., Cavanagh P.R., Gender differences in adult foot shape: implications for shoe design. Med Sci Sport Exerc, 2001, 33 (4), 605-611. 
23. Sinclair J., Greenhalgh A., Taylor P.J., Edmundson C.J., Brooks D., Hobbs S.J., Differences in tibiocalcaneal kinematics measured with skin and shoe-mounted markers. Hum Mov, 2013, 14 (1), 64-69, doi: 10.2478/humo-20130005.

24. Leardini A., Benedetti M., Berti L., Bettinelli D., Nativo R., Giannini S., Rear-foot, mid-foot and fore-foot motion during the stance phase of gait. Gait Posture, 2007, 25 (3), 453-462, doi: 10.1016/j.gaitpost.2006.05.017.

Paper received by the Editors: February 10, 2014

Paper accepted for publication: June 5, 2014

\section{Correspondence address}

Jonathan Sinclair

Division of Sport, Exercise

and Nutritional Sciences

School of Sport Tourism and Outdoors

University of Central Lancashire

Preston, Lancashire

PR1 2HE, United Kingdom

e-mail: JKSinclair@uclan.ac.uk 